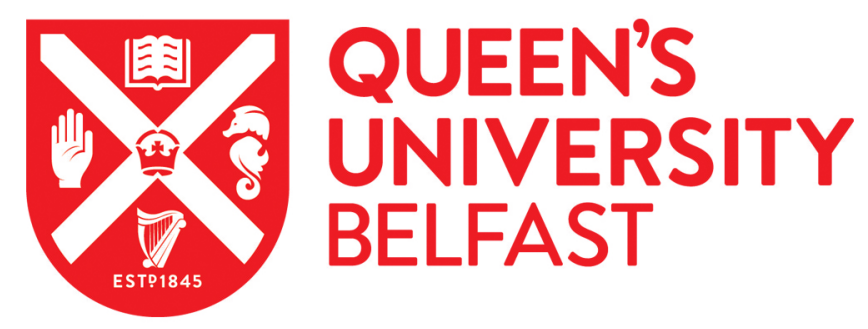

\title{
Parent ratings of child cognition and language compared with Bayley- III in preterm 3-year-olds
}

Perra, O., McGowan, J. E., Grunau, R. E., Boylan Doran, J., Craig, S., Johnston, L., Jenkins, J., Holmes, V. A., \& Alderdice, F. A. (2015). Parent ratings of child cognition and language compared with Bayley-III in preterm 3year-olds. Early human development, 91(3), 211-216. https://doi.org/doi:10.1016/j.earlhumdev.2015.01.009

Published in:

Early human development

Document Version:

Peer reviewed version

Queen's University Belfast - Research Portal:

Link to publication record in Queen's University Belfast Research Portal

Publisher rights
(C) 2015 Elsevier Ireland Ltd

This is the author's version of a work that was accepted for publication in Early Human Development. Changes resulting from the publishing process, such as peer review, editing, corrections, structural formatting, and other quality control mechanisms may not be reflected in this document. Changes may have been made to this work since it was submitted for publication. A definitive version was subsequently published in Early Human Development , [VOL 91, ISSUE 3, (March 2015)] doi:10.1016/j.earlhumdev.2015.01.009

\section{General rights}

Copyright for the publications made accessible via the Queen's University Belfast Research Portal is retained by the author(s) and / or other copyright owners and it is a condition of accessing these publications that users recognise and abide by the legal requirements associated with these rights.

Take down policy

The Research Portal is Queen's institutional repository that provides access to Queen's research output. Every effort has been made to ensure that content in the Research Portal does not infringe any person's rights, or applicable UK laws. If you discover content in the Research Portal that you believe breaches copyright or violates any law, please contact openaccess@qub.ac.uk. 
Full Title:

Parent ratings of child cognition and language compared with Bayley-III in preterm 3-year-olds.

Short Title:

Parent ratings of child cognition

Oliver Perra, PhD ${ }^{a 1}$, Jennifer E. McGowan,PhD, RNª, Ruth E. Grunau PhD, RPsych ${ }^{a, b}$, Jackie Boylan ${ }^{c}$, Stanley Craig, MD, MRCP (UK), FRCPCH ${ }^{d}$, Linda Johnston PhD, RN ${ }^{a}$, John Jenkins, MD, FRCPCH, FRCP, $\mathrm{FRCPI}^{\mathrm{c}}$, Valerie A. Holmes, PhD, RGN ${ }^{\mathrm{c}}$, Fiona A. Alderdice, $\mathrm{PhD}^{\mathrm{a}}$

a School of Nursing \& Midwifery, Queen's University Belfast, Belfast, United Kingdom;

${ }^{1}$ Corresponding author: Dr Oliver Perra, School of Nursing \& Midwifery, Queen's University Belfast, MBC, 97 Lisburn Road, Belfast, BT9 7BL, United Kingdom. Email: o.perra@qub.ac.uk; Phone: +44 (0)28 9097 2313; Fax:+44 (0)2890972328;

${ }^{\mathrm{b}}$ Department of Pediatrics, University of British Columbia, and Child \& Family Research Institute, Vancouver, Canada;

c School of Medicine, Dentistry and Biomedical Sciences, Queen's University Belfast, Belfast, United Kingdom;

d NICORE Project, Royal Maternity Hospital, Belfast, United Kingdom.

Keywords: Child Development; Premature Babies; Preschoolers; Parental ratings.

Abbreviations:

Bayley-III : Bayley Scales of Infant and Toddler Development-III ;

CDI-III: MacArthur Communicative Development Inventory-III;

LRT: Likelihood Ratio Test;

NICU: Neonatal Intensive Care Unit;

PARCA: Parent Report of Children's Abilities;

PARCA3: Parent Report of Children's Abilities - version for 3-year-olds;

SD: Standard Deviation;

SES: Socio-Economic status.

Acknowledgements: This study was part of a research project funded by the Department of Health, Social Services and Public Safety. Dr McGowan received a PhD Studentship from the Department for 
Employment and Learning, Northern Ireland. We are grateful to all families that took part in the study.

Words count: 2683 


\section{Abstract}

Background: Parent ratings on questionnaires may provide valid and cost-effective tools for screening cognitive development of children at risk of developmental delay.

Aims:In this study we examined the validity of combining parent-based reports of non-verbal cognitive abilities (PARCA3) and verbal abilities (CDI-III) in relation to the Bayley-III cognitive scale in 3 -year-olds born late pre-term.

Methods: Mothers of 203 late-preterm children were asked to complete the PARCA3 and the CDI-III when children were aged three; children were then assessed using the Bayley-III close to their third birthday.

Results: The two parent questionnaires were significantly and moderately correlated with the Bayley-III cognitive scores. Together the parent ratings accounted for $14 \%$ of the variance in Bayley-III cognitive scores, after controlling for other covariates in regression analysis. In particular, the PARCA3 contributed significantly to explain variance in the Bayley-III cognitive scores when controlling for the CDI-III. However, the CDI-III was also independently associated with the Bayley-III cognitive scores . Conclusions: Parent ratings of child cognition and language together may provide costeffective screening of development in "at risk" pre-schoolers. 


\section{Introduction}

Children born preterm are often monitored during the preschool years due to their increased risk of neurodevelopmental delay. However, individual assessment by trained testers is expensive and represents a significant strain on limited resources. Furthermore, such assessment may not provide an entirely reliable or valid sample of a child's typical behaviour and skills, since interacting with a stranger as well as shyness and temperamental difficulties can affect children's performance in a testing session in an unfamiliar setting ${ }^{(1)}$.

Questionnaires completed by parents or guardians who are familiar with the child are widely used for the assessment of temperament ${ }^{(2)}$, problem behaviours ${ }^{(3)}$, and language development ${ }^{(4)}$. However, few parent-based instruments have been developed to assess cognitive development in children, therefore children's assessment in populations at risk of cognitive delay still relies on expensive assessor-based tools such as the Bayley Scales of Infant and Toddler Development-III (Bayley-III $\left.{ }^{(5)}\right)$.

The Parent Report of Children's Abilities-Revised (PARCA-R $\mathrm{R}^{(6,7)}$ ) is a parent-based questionnaire for assessment of children's cognitive development. It was developed to provide an assessment of non-verbal cognitive abilities by enquiring about children's abilities to solve problems and perform tasks (e.g. building block towers) at age 2 years. A version for 3-year-olds was subsequently developed, the PARCA3 ${ }^{(7)}$. Both the PARCA-R and the PARCA3 comprise a parent questionnaire and parent-administered tasks. The PARCA-R displayed significant relationships with the Bayley Scales of Infant Development-II Mental Development Index ${ }^{(6)}$, and the Bayley-III Cognitive and Language composite at age two years $^{(8)}$ in children born full term. Further research suggests this instrument may act as a useful screening tool for at-risk populations such as children born pre-term. Current 
definitions from the World Health Organization differentiate extremely preterm (born $\leq 27$ weeks gestation) from very preterm (born 28 to 31 weeks gestation ${ }^{(9)}$ ). Other preterm infants can be categorised in moderate (born 32 to 33 weeks gestation ${ }^{(10,11)}$ ), and late-preterm or mild-preterm (born at 34 to 36 weeks gestation ${ }^{(10,11)}$ ). Modified versions of the PARCA-R displayed concurrent validity with the Bayley Scales of Infant Development-II Mental Development Index in very preterm ${ }^{(12)}$, moderate preterm $^{(13)}$, as well as late and moderately preterm toddlers $^{(14)}$ at age two years. Finally, the PARCA3 has been reported to correlate with the McCarthy Perceptual, Performance and Quantitative scales assessed concurrently at age 3 years $^{(7)}$. These studies together provide evidence that the PARCA is a useful instrument to assess cognitive development in typically developing and at-risk children. However, despite mounting evidence of the utility of this parental report, the relationship of the PARCA3 with the Bayley-III, currently the most widely used individual measure of development in pre-schoolers, has not been evaluated. The PARCA3 assesses children's cognitive development at three years, when more sophisticated abilities emerge. It is therefore important to investigate if, similarly to the PARCA-R for younger children, this instrument can provide a reliable picture of the general abilities of children that may be at mild to severe risk for developmental delay.

The aim of the present study was to test the convergent validity of the parent questionnaire included in the Parent Report of Children's Abilities version for 3-year-olds (PARCA3) to assess development of 3-year-old late-preterm children (born 34-36 weeks gestational age). Although late-preterm births account for about two-thirds of all pre-term births $^{(10)}$, less is known about the longer-term outcomes of this group in comparison to other preterm groups. The relative dearth of studies that investigated developmental outcomes in late preterm infants may be the consequence of the fact that this group of infants are not 
routinely followed-up after neonatal intensive care ${ }^{(15)}$. For this reason, it is important to investigate if less costly parental instruments can be used to monitor cognitive developmental outcomes in this group. The present study is part of a research project that investigated developmental outcomes of late pre-term infants.

We chose to focus on the parent questionnaire of the PARCA3 and exclude the parent-administered tasks in order to minimise the burden for parents. The PARCA3 has been designed to assess toddlers' non-verbal cognitive skills. However, because verbal abilities are a crucial component of cognitive abilities and intelligence ${ }^{(16)}$, parents were asked to complete an assessment of children's verbal and communicative skills in addition to the PARCA3. The verbal abilities assessment tool was the shortened British version of the MacArthur Communicative Development Inventory-III (CDI-III $\left.{ }^{(17)}\right)$.

Our main goal was to compare the PARCA3 associations with the cognitive scale of the Bayley Scales of Infant and Toddler Development-III, which has become the preferred choice in assessment of developmentally at-risk children ${ }^{(13)}$. In order to investigate these associations, we report correlations between the measures and conducted regression analyses controlling for other maternal and child characteristics that could influence both types of measure. By including maternal assessment of children's verbal and communicative skills (CDI-III), we were also able to assess whether the PARCA3 provided a unique contribution to predicting variation in the tester-based cognitive assessment. For this reason, we measured the association between PARCA3 and Bayley-III Cognitive scores while controlling for the association between child's verbal skills (as reported by mothers) and the tester-assessed cognitive skills.

\section{Patients and Methods}

\section{Participants}


Participants in this study had been recruited for a research project on outcomes of infants born late preterm admitted to neonatal intensive care or high-dependency care ${ }^{(15)}$. Eligibility criteria for the study were: birth at 34 weeks +0 days to 36 weeks +6 days gestational age, birth between January and December 2006 in Northern Ireland (NI), absence of a recognised congenital syndrome, absence of an ante- and post-natal confirmed infection. Gestational age was determined by foetal ultrasound (usually at 20 weeks). Of all eligible children invited to take part in the study $(\mathrm{N}=494), 240(48.6 \%)$ were recruited and 225 of them $(94 \%)$ were assessed when aged approximately 3 years (mean age in months at time of assessment 38.98 [SD=0.85] range 35.7 - 41.9). Complete data on the three developmental measures in this study (PARCA3, CDI-III and Bayley-III cognitive scores), as well as other child and family measures considered as covariates, were available for $\mathrm{N}=203(90 \%)$. Overall, 18 pairs of twins were included in the $\mathrm{N}=203$ sample. Because twin pregnancies have different characteristics, to avoid giving twins disproportionate leverage over the results, we excluded from the final sample a randomly-selected twin from each of the pairs. Exclusion of 18 twins from each pair resulted in a final sample with $\mathrm{N}=185$. Characteristics of these 185 children and their mothers are provided in Table 1.

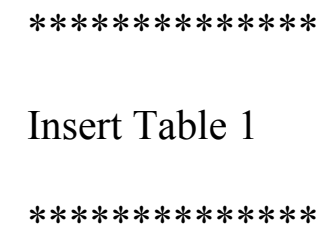


Ethical approval was granted from the Office for Research Ethics Committees Northern Ireland. The Health and Social Care Business Services Organisation conducted a trace of eligible children to ensure that parents/guardians with a child who died in infancy were not contacted. All the parents or guardians of eligible children were sent an invitation letter and two reminder letters from the neonatal consultant at their hospital of birth. Parents that provided written consent to take part in the study were contacted to arrange an appointment for an assessment of children as close as possible to the child's third birthday. Two weeks before the appointment parents were sent questionnaires to complete. A trained tester carried out the Bayley-III assessment in the child's home. Participating families received a shopping gift voucher to thank them.

Measures

\section{Participant Characteristics}

Perinatal information was collected from maternal medical records and from the Neonatal Intensive Care Outcomes Research and Evaluation database which contains data on infants admitted to all 7 Neonatal Intensive Care Units (NICU) across Northern Ireland. Additional descriptive socio-demographic information was collected using a parent report questionnaire designed specifically for the study. In order to assess socio-demographic status of children, deprivation quintiles were calculated using the Northern Ireland Multiple Deprivation Measure $^{(18)}$. A summary social risk index was calculated for each family to represent children's exposure to a number of socio-demographic risk factors, including: teenage mother at time of delivery; mother living alone; mother single, divorced or separated; mother who did not complete high-school equivalent; living in more deprived area (lowest quintile in the Multiple Deprivation Measure); living in rented accommodation. The social risk index calculated displayed sufficient reliability (Cronbach's alpha $\left.{ }^{(19)}=.68\right)$. 
Child Neurodevelopment.

The Bayley Scales of Infant and Toddler Development, Third Edition (Bayley-III) was administered by trained testers. The Bayley III comprises a series of age-appropriate tester-administered tasks that measure cognition, language (expressive and receptive), and motor (fine and gross) abilities. The Bayley-III provides raw scores in each of these scales, which are used to derive normative composite scores by age, and three composite scores for cognition, language and motor performance. In the present study we used the raw scores of the Bayley-III cognitive scale to provide greater inter-individual variation in the range of scores, due to the recognized problems with the standardized Bayley-III scores ${ }^{(20,21)}$. Use of raw scores was acceptable due to the narrow age range of children tested in the present study; nonetheless, in statistical analyses we controlled for child age.

Parent Report of Children's Abilities for Three Year Olds (PARCA3).

The PARCA3 is a parent assessment of three-year old children's non-verbal abilities. The full PARCA3 comprises a parent report and parent-administered tasks with the child. However, to minimise burden to parents, in the present study we used only the parent report form $^{(7)}$. The parent-report component comprises 24 items that assess aspects of cognitive development such as spatial ability, planning and organising, reasoning, memory, quantitative skills and pretend play. For each item mothers were asked to report whether or not they had seen their child perform an activity, with a response of 'Yes' (scored as 1) and 'No' or 'Don't Know' (scored as 0). An example includes: "Does your child draw simple pictures that other people can recognise, such as a person, house or car?" The mother of each child in the study completed the questionnaires. Scores to individual items were summed to obtain a total PARCA3 score. The PARCA3 maternal report displayed good reliability (Cronbach's alpha $=0.70)$. 
Communicative Development Inventories (CDI - III).

We used the UK short form of the MacArthur Communicative Development Inventories: Words and Sentences (MCDI:UKSF) version for age 3 years. Mothers completed a 100-item vocabulary checklist, a 12-item sentence complexity scale that enquired whether the child used more complex alternatives of similar sentences (e.g. "That coffee hot" vs. "Coffee hot"), and a 12-item sub-scale that investigated the child's semantics, pragmatics and language comprehension (e.g. child uses words that end in -est, like biggest). The reliability of the latter two scales was optimal (Cronbach's alpha $=.90)$. We calculated a total CDI score by summing the vocabulary check-list, sentence complexity and language comprehension scales included in this instrument.

Analytic Strategy

Partial correlations were used to examine associations between the PARCA3, CDIIII, and the Bayley-III while controlling for age. Successively we conducted a series of regression analyses to investigate relationships between the Bayley-III and the two parentbased measures while controlling for covariates. Children's individual covariates were: sex, low birth weight, gestational age (three categories: 34,35 and 36 weeks), NICU admission (yes/no), age at testing (in months). Maternal covariates were parity and the social risk index. Nested models were tested. The first model included child and socio-demographic characteristics. The CDI-III total score and PARCA3 were entered in a successive block. Analyses were conducted using Stata $13^{(22)}$.

\section{Results}

Descriptive analyses

The PARCA3 scores (mean $15.42[S D=3.45]$ range 7-23), the CDI-III scores (mean $88.59[S D=25.42]$ range 4-124) and the Bayley-III cognitive scale raw scores (mean 77.82 
$[S D=3.71]$, range 64-85), all displayed negatively skewed distributions. The mean Bayley composite cognitive score was $103.13(S D=9.70)$, range 80-135.

\section{Correlation Analyses}

Partial correlations between the PARCA3, CDI-III vocabulary score and the BayleyIII raw scores while controlling for age are reported in Table 2. There was a significant positive correlation between PARCA total and CDI-III, partial $r=0.37, p<.001$. The PARCA was more highly correlated with the Bayley-III Cognition $($ partial $r=.41)$ than Receptive and Expressive communication (partial $r=.28$ for both). The correlation between the PARCA and the Fine Motor skills sub-scale was higher than that with the Gross Motor skills. The CDI-III displayed a higher partial correlation with the Bayley-III Expressive Communication scale (partial $r=.43$ ) than with the Cognitive and Receptive Communication scales (partial $r=.35$ and partial $r=.32$ respectively). The CDI-III displayed lower correlations with the motor scales.

Insert Table 2

$* * * * * * * * * * * * * *$

\section{Regression analyses}

Preliminary checks of assumptions (influential outliers, normality of residuals, homoscedasticity, absence of multicollinearity and linearity) were satisfied once the BayleyIII Cognitive raw scores and the CDI total scores were transformed to allow for asymmetric and negatively skewed distributions. For both, we conducted a square root transformation. For ease of interpretation, the transformed Bayley-Cognitive scores were centred so that the sample mean was 0 and the sample standard deviation was 1 . PARCA3 raw scores and 
transformed CDI-III scores were also centred so that the sample mean in each of the two scales was equal to 0 and the standard deviation was equal to 1: this allowed scores in the PARCA3 and CDI-III (as well as Bayley-III scores) to be expressed in the same scale, thus facilitating direct comparisons. Results of the nested regressions on the transformed BayleyIII Cognitive raw scores are reported in Table 3. The analysis of associations between child and maternal characteristics indicated a positive relationship between age and cognitive scores. Furthermore, results indicated a significant association with sex, whereby males displayed lower scores compared to females, and a positive association between cognitive scores and parity, whereby having another sibling was associated with higher cognitive scores compared to not having siblings. Finally, higher scores on the Social Risk Index were associated with lower Cognitive scores. These covariates explained approximately $18 \%$ of variance in the Bayley-III cognitive scores. The transformed CDI-III scores and the PARCA3, entered together in the second block, explained a further $15 \%$ of variation in the Bayley-III cognitive scores when controlling for other child and maternal characteristics. Results indicated that the CDI-III and the PARCA3 provided a significant contribution to prediction of the Bayley-III scores, $F(2,173)=20.0, p<.0001$.

The association of the PARCA3 with the Bayley-III Cognitive scale was slightly stronger $(\beta=0.27)$ compared to the CDI-III ( $\beta=0.22)$, but this difference was not significant, Wald $\chi^{2}(1,173)=0.32, p=.57$. Figure 1 displays predicted margins plots of the transformed PARCA3 scores and transformed CDI-III scores in relation to the centred Bayley-III Cognitive raw scores; the shaded area represents 95\% Confidence Intervals $(C I)$ of predicted scores. The darker markers in the figure represent the scatter of transformed cognitive Bayley-III scores with PARCA3 and transformed CDI-III scores respectively. The PARCA3 scores displayed a slightly stronger linear association with Bayley-III cognitive 
scores compared to the CDI-III (as indicated by inclination of the lines). The confidence of PARCA-3 prediction of Bayley-III scores was greater in the middle and high range of the PARCA3 scores (as indicated by the thinner shaded area) compared to the lower range of scores.

$* * * * * * * * * * * * * * * *$

Insert Table 3 and Figure 1

\section{Discussion}

Our findings suggest that the combination of maternal reports of child non-verbal cognitive abilities (PARCA3) together with a maternal questionnaire of child language and communication development (CDI-III) is significantly associated with the tester-based Bayley-III Cognitive scale, above and beyond child sex and socio-demographic risk factors. Since social risk factors are known to affect developmental outcomes ${ }^{(23)}$, it appears important to take the latter factors into consideration. Notably the PARCA3, a non-verbal cognitive scale, was related to Bayley-III Cognitive scores even when controlling for maternal reports of the child's language and other covariates such as sex and Socio-Economic Status (SES). These results, collected on a sample of toddlers born late pre-term, concur with other reports in indicating the viability of the PARCA in screening cognitive development in children at risk for developmental delay.

The Bayley scales have long been the primary choice for individualized normative assessment of children at risk for developmental delay, such as those born preterm ${ }^{(13)}$. However, concerns have been raised that the most recent version, the Bayley-III, provides 
scores that are not well calibrated with previous editions of the test ${ }^{(21)}$. Therefore it is challenging to find a "gold standard" for comparison when evaluating convergent validity of the parent report scales as indices of cognition. Moreover, predictive validity of the BayleyIII is yet unclear. In a similar manner to other tester-based assessment, the Bayley-III may also not be ideal in providing an accurate sample of a child's range of skills and behaviours: testing takes place with a stranger in an unfamiliar setting, often after disruption to the child's typical routine to attend a clinic appointment. In contrast, it has been proposed that parents and guardians who are familiar with the child and have observed the child across different situations may be able to provide reliable information as to the range and scope of abilities ${ }^{(1)}$. Furthermore, individualized assessments such as the Bayley-III are an expensive method to evaluate development in large populations, as it requires trained testers in a one-to-one testing session with the child.

Our findings are consistent with other studies of the PARCA-R at age two years ${ }^{(6,8,14)}$ and the PARCA3 at three years ${ }^{(7)}$. Of particular importance is that a number of studies, which have been conducted on different populations and using different individuallyadministered tests, provide evidence of the convergent validity of using the PARCA together with a vocabulary questionnaire to assess cognitive development of preschool-aged children. Our results are very similar in magnitude to the correlations reported previously at age 3 years between the PARCA3, CDI-III and the McCarthy scales ${ }^{(7)}$. Thus the PARCA3 in combination with the CDI-III appear to be reasonably valid and useful instruments to screen cognition in children aged three. The results also suggest that the PARCA3 parental report may be used to assess the cognitive development of children born pre-term when aged 3 years. Other studies have provided evidence of the PARCA-R validity in assessing cognitive development of pre-term children at 2 years of age ${ }^{(12-14)}$. Overall, results from our study and 
these other studies suggest that parental assessments may be meaningfully used to monitor trajectories of cognitive development of pre-term children across early childhood.

Some caution is due as the correlations between the PARCA3 and the Bayley-III scores were moderate. Furthermore, the confidence intervals of Bayley-III cognitive scores predicted by PARCA3 and CDI-III were larger at the lower end of the scores. However, the limitations of the Bayley-III ${ }^{(20)}$ and the absence of a gold standard warrant further investigation of the clinical utility of the parent assessment. Indeed, an important limitation of our study lies in the fact that we did not test the discriminative power of the PARCA3 in relation to a robust criterion.

The results of the present study also suggest the importance of considering sex and socio-demographic risk factors when assessing cognitive levels of children born preterm. Similar to other studies of preterm children across a wide spectrum of gestational age ${ }^{(24,25)}$, we identified that boys display poorer cognitive development in our sample of late pre-term infants. Exposure to socio-demographic risk factors showed a particularly strong association with Bayley-III cognitive scores. Contextual factors such as access to social or economic resources (e.g. social support) play an important role in influencing cognitive development in typically-developing children ${ }^{(23)}$ and these can also play a key role in amplifying or conversely buffering against the detrimental effects on cognitive development of factors associated with preterm birth $^{(26,27)}$.

\section{Conclusions}

This study provides evidence of the validity of the combination of two parental questionnaires in assessing cognitive level in 3-year-olds, against a criterion provided by the Bayley-III. These parent-based questionnaires appear to provide cost-effective and useful measures for general screening of pre-schoolers and can be opportunely used in screening cognitive development of children born pre-term during their first years of life. 
Parent ratings of child cognition 


\section{List of References}

(1) Bornstein MH, Haynes OM. Vocabulary competence in early childhood: Measurement, latent construct, and predictive validity. Child Dev 1998 JUN 1998;69(3):654-671.

(2) Gartstein MA, Rothbart MK. Studying infant temperament via the Revised Infant Behavior Questionnaire. Infant Behavior \& Development 2003 FEB 2003;26(1):64-86.

(3) Achenbach TM, Howell CT, Quay HC, Conners CK. National Survey of Problems and Competences among 4 to 16 Year-Olds - Parents Reports for Normative and Clinical-Samples. Monogr Soc Res Child Dev 1991 1991;56(3):R5-R119.

(4) Rescorla L, Ratner NB, Jusczyk P, Jusczyk AM. Concurrent validity of the Language Development Survey: Associations with the MacArthur-Bates Communicative Development Inventories: Words and Sentences. American Journal of Speech-Language Pathology 2005 MAY 2005;14(2):156-163.

(5) Albers CA, Grieve AJ. Bayley scales of infant and toddler development, third edition. Journal of Psychoeducational Assessment 2007 JUN 2007;25(2):180-190.

(6) Saudino KJ, Dale PS, Oliver B, Petrill SA, Richardson V, Rutter M, et al. The validity of parentbased assessment of the cognitive abilities of 2-year-olds. British Journal of Developmental Psychology 1998 SEP 1998;16:349-363.

(7) Oliver B, Dale P, Saudino K, Petrill S, Pike A, Plomin R. The Validity of a Parent-based Assessment of Cognitive Abilities in Three-year Olds*. Early Child Development and Care 2002 08/01; 2013/12;172(4):337-348.

(8) Martin AJ, Darlow BA, Salt A, Hague W, Sebastian L, McNeill N, et al. Performance of the Parent Report of Children's Abilities-Revised (PARCA-R) versus the Bayley Scales of Infant Development III. Arch Dis Child 2013 2013-Dec;98(12):955-8.

(9) WHO | Preterm birth. Available at: http://www.who.int/mediacentre/factsheets/fs363/en/. Accessed 9/2/2014, 2014.

(10) Davidoff. Changes in the gestational age distribution among U.S. singleton births: Impact on rates of late preterm birth, 1992 to 2002 (vol 30, pg 8, 2006). Semin Perinatol 2006 OCT;30(5):313313.

(11) Kramer MS. The Contribution of Mild and Moderate Preterm Birth to Infant Mortality. JAMA 2000;284(7):843.

(12) Johnson S, Marlow N, Wolke D, Davidson L, Marston L, O'Hare A, et al. Validation of a parent report measure of cognitive development in very preterm infants. Dev Med Child Neurol 2004 JUN;46(6):389-397. 
(13) Johnson S, Marlow N. Developmental screen or developmental testing? Early Hum Dev 2006 MAR 2006;82(3):173-183.

(14) Blaggan S, Guy A, Boyle EM, Spata E, Manktelow BN, Wolke D, et al. A Parent Questionnaire for Developmental Screening in Infants Born Late and Moderately Preterm. Pediatrics 2014 JUL;134(1):E55-E62.

(15) McGowan JE, Alderdice FA, Doran J, Holmes VA, Jenkins J, Craig S, et al. Impact of Neonatal Intensive Care on Late Preterm Infants: Developmental Outcomes at 3 Years. Pediatrics 2012 NOV 2012;130(5):E1105-E1112.

(16) WALKER D, GREENWOOD C, HART B, CARTA J. Prediction of School Outcomes Based on Early Language Production and Socioeconomic-Factors. Child Dev 1994 APR;65(2):606-621.

(17) Feldman HM, Dale PS, Campbell TF, Colborn DK, Kurs-Lasky M, Rockette HE, et al. Concurrent and predictive validity of parent reports of child language at ages 2 and 3 years. Child Dev 2005 JUL-AUG 2005;76(4):856-868.

(18) Northern Ireland Statistics \& Research Agency. Northern Ireland multiple deprivation measure 2005. 2005.

(19) Cronbach LJ. Citation Classic - Coefficient-Alpha and Internal Structure of Tests. Current Contents 1978 1978(13):8-8.

(20) Anderson PJ, De Luca CR, Hutchinson E, Roberts G, Doyle LW, Victorian Infant Collaborative Grp. Underestimation of Developmental Delay by the New Bayley-III Scale. Arch Pediatr Adolesc Med 2010 APR 2010;164(4):352-356.

(21) Moore T, Johnson S, Haider S, Hennessy E, Marlow N. Relationship between Test Scores Using the Second and Third Editions of the Bayley Scales in Extremely Preterm Children. J Pediatr 2012 APR 2012;160(4):553-558.

(22) StataCorp LP. Mata reference manual: release 11. College Station, Tex.: StataCorp LP; 2009.

(23) Duncan GJ, Brooksgunn J, Klebanov PK. Economic Deprivation and Early-Childhood Development. Child Dev 1994 APR 1994;65(2):296-318.

(24) Hindmarsh GJ, O'Callaghan MJ, Mohay HA, Rogers YM. Gender differences in cognitive abilities at 2 years in ELBW infants. Early Hum Dev 2000 DEC 2000;60(2):115-122.

(25) Raz S, Lauterbach MD, Hopkins TL, Glogowski BK, Porter CL, Riggs WW, et al. A Female Advantage in Cognitive Recovery from Early Cerebral Insult. Dev Psychol 1995 NOV 1995;31(6):958-966.

(26) Beaino G, Khoshnood B, Kaminski M, Marret S, Pierrat V, Vieux R, et al. Predictors of the risk of cognitive deficiency in very preterm infants: the EPIPAGE prospective cohort. Acta Paediatrica 2011 MAR 2011;100(3):370-378.

(27) Wong HS, Edwards P. Nature or Nurture: A Systematic Review of the Effect of Socio-economic Status on the Developmental and Cognitive Outcomes of Children Born Preterm. Matern Child Health J 2013 NOV 2013;17(9):1689-1700. 
Table 1. Infant and maternal characteristics $(\mathrm{N}=185)$

Infants Characteristics

\begin{tabular}{cccc} 
& & $n$ & $(\%)$ \\
\hline NICU admission & No & 98 & $(53.0)$ \\
& Yes & 87 & $(47.0)$ \\
& Memale & 89 & $(48.1)$ \\
& Male & 96 & $(51.9)$ \\
Gestational age & 35 weeks & 48 & $(26.0)$ \\
& 36 weeks & 55 & $(44.3)$ \\
Birth weight & $<$ 2500g & 82 & $(44.3)$ \\
& $\geq 2500 g$ & 103 & $(55.7)$ \\
& Singleton & 162 & $(87.6)$ \\
Multiple births & Twins & 23 & $(12.4)$ \\
& & &
\end{tabular}

\section{Maternal Characteristics}

\begin{tabular}{lcc}
\hline Mother in her teens at time of child's birth & $\boldsymbol{n}$ & (\%) \\
Mother did not attain basic level of educational qualifications & 4 & $(2.2)$ \\
Mother living alone & 6 & $(3.2)$ \\
Mother single, separated or divorced & 23 & $(12.4)$ \\
Living in deprived areas (most deprived quintile) & 34 & $(18.4)$ \\
Living in rented accommodation & 24 & $(13.0)$ \\
\end{tabular}


Table 2. Partial correlations between PARCA3, CDI-III and Bayley-III raw scores controlling for differences in age.

\section{PARCA3 CDI-III}

Non-Verbal

CDI-III $\quad 0.37 * * *$

$$
\text { Bayley-III }
$$

\begin{tabular}{lll}
\hline Cognitive & $0.41 * * *$ & $0.35^{* * *}$
\end{tabular}

Receptive $\quad 0.28 * * * \quad 0.32 * * *$
Language

\begin{tabular}{l|ll} 
Expressive & $0.28 * * *$ & $0.43^{* * *}$ \\
Language & &
\end{tabular}

Fine Motor $\quad 0.39 * * * 19 *$

\begin{tabular}{|c|c|c|}
\hline Gross Motor & $0.20 * *$ & $0.20 * *$ \\
\hline
\end{tabular}


Table 3: Results of nested regressions on Bayley-III Cognitive Raw scores (square root transformed and centred). Standardized coefficients are reported first, with non-standardized coefficients and their standard error (SE) reported next. $\mathrm{F}$ tests, $\mathrm{R}^{2}$ and change in $\mathrm{R}^{2}$ are reported for each block of variables in the nested regression. Parca 3 and CDI-III transformed scores were centred at mean $=0$ and $\mathrm{SD}=1$.

\begin{tabular}{|c|c|c|c|c|c|c|c|}
\hline & & $\beta^{1}$ & Coef. ${ }^{1}$ & $S E^{1}$ & $F(d f)$ & $R^{2}$ & $\Delta R^{2}$ \\
\hline NICU & No & Ref & Ref & $\operatorname{Ref}$ & & & \\
\hline admission & Yes & 0.01 & 0.02 & 0.13 & & & \\
\hline Child & Female & Ref & $\operatorname{Ref}$ & $\operatorname{Ref}$ & & & \\
\hline Sex & Male & $-0.21 * *$ & -0.41 & 0.13 & & & \\
\hline Age & (in months) & $0.18 * *$ & 0.22 & 0.08 & & & \\
\hline Low Birth & No & $\operatorname{Ref}$ & $\operatorname{Ref}$ & $\operatorname{Ref}$ & & & \\
\hline Weight & Yes & 0.02 & 0.04 & 0.14 & & & \\
\hline Child & 34 weeks & $\operatorname{Ref}$ & $\operatorname{Ref}$ & $\operatorname{Ref}$ & & & \\
\hline Gestational & 35 weeks & 0.03 & 0.06 & 0.16 & & & \\
\hline Age & 36 weeks & 0.02 & 0.04 & 0.18 & & & \\
\hline \multirow{3}{*}{ Parity } & 1 child & Ref & $\operatorname{Ref}$ & $\operatorname{Ref}$ & & & \\
\hline & 2 children & $0.19 *$ & 0.38 & 0.18 & & & \\
\hline & 3 children or more & -0.03 & -0.06 & 0.18 & & & \\
\hline Social Risk Index & (Total scores) & $-0.18 * *$ & -0.16 & 0.06 & & & \\
\hline BLOCK 1 & & & & & $\begin{array}{l}4.3 * * * \\
(9,175)\end{array}$ & 0.18 & -- \\
\hline CDI-III & (Sqrt transformed) & $0.22 * *$ & 0.22 & 0.07 & & & \\
\hline PARCA3 & (Total scores) & $0.27 * * *$ & 0.29 & 0.08 & & & \\
\hline BLOCK 2 & & & & & $\begin{array}{l}20.0 * * * \\
(2,173)\end{array}$ & 0.33 & 0.15 \\
\hline Constant & & & -0.53 & 0.36 & & & \\
\hline
\end{tabular}

${ }^{1}$ Parameters reported here are those obtained in the second block whereby all the variables of interest had been included in the regression. 
Parent ratings of child cognition 
Figure 1. Plot of predictive margins and 95\% CI (shaded area) of transformed Bayley-III cognitive raw scores $(\mathrm{y}$ axis) as a function transformed PARCA3 and transformed CDI-III. Bayley Cognitive raw scores are centred at the sample mean. PARCA3 and CDI-III were transformed so that the raw averages and $\mathrm{SD}$ s in each scale were equated to 0 and 1 respectively.
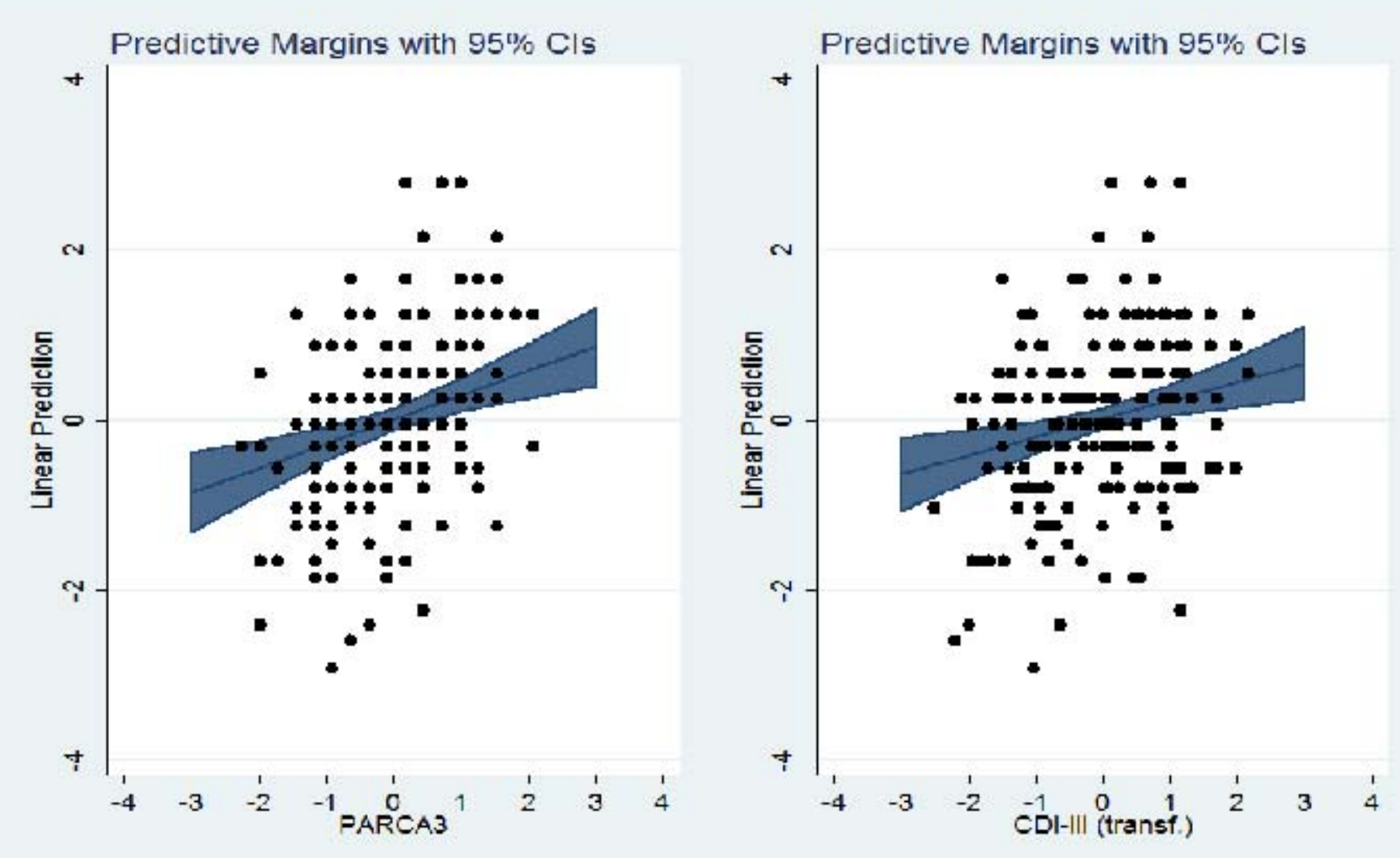